\title{
Misoprostol for pre-term labor induction in the second trimester: Role of medical history and clinical parameters for prediction of time to delivery
}

\author{
Alexander di Liberto ${ }^{1}$, Jan Endrikat ${ }^{2}$, Sandra Frohn², Erich Solomayer ${ }^{2}$, Kubilay Ertan ${ }^{1,2}$ \\ ${ }^{1}$ Department of Obstetrics and Gynecology, Leverkusen Municipal Hospital, Leverkusen, Germany \\ ${ }^{2}$ Department of Obstetrics and Gynecology, Saarland University Hospital, Homburg, Germany
}

\section{Abstract}

Objective: Serious fetal malformations and/or chromosome aberrations detected by modern diagnostic tools in early pregnancy require discussions on induced abortion with pregnant women. Competent counseling includes prediction of the time needed for the whole abortion process. In an attempt to refine our predictions, we evaluated the impact of 11 medical history and clinical variables on time to delivery.

Material and Methods: We performed a retrospective chart analysis on 79 women submitted for pre-term abortion because of fetal anomalies. Abortion was induced by vaginal application of misoprostol (prostaglandine $\mathrm{E}_{1}$, Cytotec ${ }^{\mathrm{TM}}$, Pfizer, New York, USA). We investigated 11 medical history and clinical variables for their impact on the percentage of women delivering within 24 hours (primary endpoint) and on the mean induction-delivery time interval (secondary endpoint).

Results: Fifty-three percent (42/79) of women delivered within 24 hours; 83.6\% (66/79) delivered within 48 hours. A total of $83.3 \%$ of women with a history of late abortion delivered within 24 hours, whereas $50.7 \%$ without this history did. Mean induction-delivery time interval was 12.3 hours versus 35.5 hours, respectively. For history of early abortion, the figures were $65.2 \%$ versus $48.2 \%$ for delivery within 24 hours and 15.6 hours versus 32.5 hours for mean induction-delivery time interval. Current weight of fetus $>500 \mathrm{~g}$, weight of last previous newborn of $\leq 3500 \mathrm{~g}$, previous pregnancies, premature rupture of membranes, and an elevated CRP of $>0.5 \mathrm{mg} / \mathrm{dL}$ also cut time to delivery. Surprisingly, maternal and gestational age had no remarkable or consistent impact on the mean induction-delivery time interval. None of the differences reached statistical significance. Eighty-three percent of women needed $1000 \mu \mathrm{g}$ or less for successful delivery.

Conclusion: Neither variables of medical history nor specific clinical variables allow for precise prediction of time to delivery in the second trimester. Certain parameters, however, show a trend to reduce the induction-delivery time interval. Our results might serve as initial guidance for patient counseling. (J Turk Ger Gynecol Assoc 2014; 15: 130-4)

Key words: Misoprostol, labor induction, time to delivery, patient counseling

Received: 06 March, 2014

Accepted: 17 June, 2014

Available Online Date: 08 August, 2014

\section{Introduction}

Today, modern prenatal diagnostic tools facilitate detection of the majority of fetal anomalies already in early pregnancy. In cases of serious fetal malformations and/or chromosome aberrations, the option of an induced abortion needs to be discussed with pregnant women.

In the second trimester, induced abortion is a two-step process, starting with application of a prostaglandin derivative followed by curettage. Currently, a number of prostaglandins (e.g., prostaglandin $\mathrm{E}_{1}$ and $\mathrm{E}_{2}$ ) and different application routes are available. Misoprostol (prostaglandine $\mathrm{E}_{1}$, Cytotec $^{\mathrm{TM}}$, Pfizer) has been licensed for the prevention and treatment of gastroduodenal ulcers since 1985 in more than 80 countries (1). Misoprostol has been extensively studied in gynecology and obstetrics and is widely recommended for the treatment of missed and incomplete miscarriages, the induction of abortion, cervical ripening before uterine instrumentation, and indication of labor in full-term pregnancies, although this is not an official indication by the label (offlabel use) (1).

Prediction of the time from abortion induction to delivery, the so-called 'induction-delivery time interval,' is crucial for counseling pregnant women, as this phase constitutes a major emotional and psychological burden.

In an attempt to refine our predictions for the women, we evaluated the impact of 11 medical history and clinical variables on length of abortion.

\section{Material and Methods}

\section{Study Design}

We performed a retrospective analysis of 79 women treated at Leverkusen Municipal Hospital, Obstetrics and Gynecology 
Table 1. Baseline characteristics of study population $(n=79)$

\begin{tabular}{|c|c|c|c|c|c|}
\hline Age (years) & $\leq 18$ & $18-30$ & $31-34$ & $>34$ & \\
\hline n (\%) & $2 / 79(2.5)$ & $43 / 79(54.4)$ & $11 / 70(13.9)$ & $23 / 79(29.1)$ & \\
\hline \multirow[t]{2}{*}{ Previous pregnancies } & 0 & 1 & 2 & 3 & $>3$ \\
\hline & $33 / 79(41.8)$ & $23 / 79(29.1)$ & $14 / 79(17.7)$ & $3 / 79(3.8)$ & $6 / 79(7.6)$ \\
\hline \multirow[t]{2}{*}{ Previous deliveries } & 0 & 1 & 2 & 3 & $>3$ \\
\hline & $44 / 79(55.7)$ & $25 / 79(31.6)$ & $5 / 79(6.3)$ & $4 / 79(5.1)$ & $1 / 79(1.3)$ \\
\hline Gestational age (weeks) & $\leq 13$ & $\leq 16$ & $\leq 21$ & $\leq 25$ & $\leq 29^{\#}$ \\
\hline n (\%) & $1 / 79(1.3)$ & $9 / 79(11.4)$ & $35 / 79(44.3)$ & $30 / 79(38.0)$ & $2 / 79(2.5)$ \\
\hline Amniotic fluid & Normal & Oligohydramnios & Polyhydramnios & Anhydramnios & \\
\hline n (\%) & $42 / 79(53.2)$ & $12 / 79(15.2)$ & $9 / 79(11.4)$ & $16 / 79(20.3)$ & \\
\hline Invasive diagnostics & No & CVS & $\mathrm{AC}$ & TORCH & Cordocentesis \\
\hline $\mathrm{n}(\%)$ & $29(36.7)$ & $4 / 79(5.1)$ & $40 / 79(53.2)$ & $2 / 79(2.2)$ & $4 / 79(4.3)$ \\
\hline
\end{tabular}

Table 2. Indications for induced abortion

\begin{tabular}{|l|l|c|}
\hline Indication & & n (\%) \\
\hline Chromosomal aberration & Total & $18(22.8)$ \\
\cline { 2 - 3 } & Trisomy 21 & $8(44.4)$ \\
\cline { 2 - 3 } & Trisomy 18 & $2(11.1)$ \\
\cline { 2 - 3 } & Trisomy 13 & $1(5.6)$ \\
\cline { 2 - 3 } & $\begin{array}{l}\text { Other } \\
\text { trisomies }\end{array}$ & $7(38.9)$ \\
\hline Organ malformation & $17(21.5)$ \\
\hline Intrauterine fetal death & $13(16.5)$ \\
\hline Multiple congenital malformations & $9(11.4)$ \\
\hline Preterm premature rupture of membranes & $5(6.3)$ \\
\hline Intrauterine growth retardation & $5(6.3)$ \\
\hline CNS malformation & $5(6.3)$ \\
\hline Fetal hydrops & $5(6.3)$ \\
\hline Fetal infections & $1(1.3)$ \\
\hline Twin to twin transfusion syndrome & $1(1.3)$ \\
\hline
\end{tabular}

(Teaching Hospital of the University of Cologne), by analyzing charts from April 2007-March 2009. The study was conducted in accordance with the ethical principles of the Declaration of Helsinki and the International Conference on Harmonization - Good Clinical Practice (ICH-GCP) Guidelines of January 17, 1997. Ethical approval was not necessary because of the retrospective design of the study.

All women were submitted for pre-term abortion due to fetal malformations. Exclusion criteria were previous cesarean section and any other uterine surgery. We administered an initial dose of misoprostol (prostaglandin $\mathrm{E}_{1}$, Cytotec $^{\mathrm{TM}}$, Pfizer, New York, USA) of $200 \mu \mathrm{g}$ vaginally on day 1 . Within 24 hours - on day 2 - we continued by adding two further doses of $400 \mu \mathrm{g}$, at least 6 hours apart (maximum dose of $1000 \mu \mathrm{g} / 24 \mathrm{~h}$ ). If no progress was seen, we repeated the doses of day 2 until delivery or conversion to another drug. Contraindications for misoprostol, such as allergies against misoprostol or any of the excipients, previous cesarean section, or other surgeries of the uterus, were respected.

\section{Variables}

We investigated the following medical history and clinical variables: age, previous pregnancies, gestational age, history of early abortion (up to 16 weeks of gestation), history of late abortion (more than 16 weeks), current fetus weight, weight of last previous newborn, years since last delivery, intrauterine fetal death, premature rupture of membranes (PROM), and C-reactive protein level (CRP).

The primary endpoint of this study was the percentage of women delivering within 24 hours $(2,3)$; the secondary endpoint was the mean induction-delivery time interval.

\section{Statistical Analysis}

The data were analyzed by descriptive statistical methods. Differences between subgroups were analyzed using the MannWhitney U-test, the t-test, and odds ratios. The software BiAS. für Windows Version 9.2. (www.bias-online.de accessed 201402-09) was used.

\section{Results}

All 79 women were valid for our evaluation. Fifty-seven percent (45/79) of women were younger than 30 years; the median age was 30 (range 17-43). Forty-two percent (33/79) were never pregnant before, $55.7 \%$ (44/79) never delivered before, $97.5 \%$ (77/79) had $\leq 25$ weeks of gestation, $46.8 \%(37 / 79)$ had an abnormal amount of amniotic fluid, and 63.3\% (50/79) had invasive diagnostics prior to the induced abortion. The baseline characteristics of the study population are shown in Table 1.

The most frequent indications for pre-term labor induction were chromosome aberrations (22.8\%, 18 women), organ malformations (21.5\%, 17 women), and intrauterine fetal death (16.5\%, 13 women) (Table 2). 
Table 3. Deliveries within 24 hours and time to delivery by medical history

\begin{tabular}{|c|c|c|c|c|c|}
\hline & & \multicolumn{2}{|c|}{ Delivery $\leq 24 \mathrm{~h}$} & \multicolumn{2}{|c|}{ Time misoprostol - delivery } \\
\hline & & $\mathbf{n}$ & $\%$ & Mean (h) & Median (h) \\
\hline \multirow[t]{2}{*}{ Age (years) $(n=79)$} & $\leq 30$ & $26 / 45$ & 57.8 & 15.3 & 15.5 \\
\hline & $>30$ & $16 / 34$ & 47.1 & 15.5 & 15.8 \\
\hline \multirow[t]{2}{*}{ Previous pregnancies $(\mathrm{n}=79)$} & 0 & $22 / 44$ & 50.0 & 17.1 & 19.9 \\
\hline & $>0$ & $20 / 35$ & 57.1 & 13.5 & 14.1 \\
\hline \multirow[t]{2}{*}{ Gestational age (weeks) $(\mathrm{n}=79)$} & $\leq 16$ & $8 / 17$ & 47.1 & 14.9 & 14.0 \\
\hline & $>16$ & $33 / 62$ & 53.2 & 15.5 & 16.4 \\
\hline \multirow[t]{2}{*}{ History of early abortion $(\mathrm{n}=79)$} & yes & $15 / 23$ & 65.2 & 15.6 & 15.5 \\
\hline & no & $27 / 56$ & 48.2 & 32.5 & 27.0 \\
\hline \multirow[t]{2}{*}{ History of late abortion $(\mathrm{n}=79)$} & yes & $5 / 6$ & 83.3 & 12.3 & 13.5 \\
\hline & no & $37 / 73$ & 50.7 & 35.5 & 29.5 \\
\hline \multirow[t]{2}{*}{ Current weight of fetus $(n=79)$} & $\leq 500 \mathrm{~g}$ & $40 / 73$ & 54.8 & 15.5 & 15.5 \\
\hline & $>500 \mathrm{~g}$ & $2 / 6$ & 33.3 & 13.5 & 13.5 \\
\hline \multirow[t]{2}{*}{ Weight of last previous newborn $(n=35)$} & $\leq 3500 \mathrm{~g}$ & $16 / 26$ & 61.5 & 12.1 & 11.8 \\
\hline & $>3500 \mathrm{~g}$ & $4 / 9$ & 44.4 & 18.6 & 18.5 \\
\hline \multirow[t]{2}{*}{ Years since last delivery* $(\mathrm{n}=35)$} & $\leq 2$ & $11 / 18$ & 61.1 & 13.0 & 14.3 \\
\hline & $>2$ & $9 / 17$ & 52.9 & 14.1 & 13.5 \\
\hline \multirow[t]{2}{*}{ Intrauterine fetal death $(\mathrm{n}=79)$} & yes & $9 / 17$ & 52.9 & 17.6 & 20.4 \\
\hline & no & $33 / 62$ & 53.2 & 15.3 & 15.0 \\
\hline \multirow[t]{2}{*}{ Premature rupture of membranes $(\mathrm{n}=79)$} & yes & $7 / 11$ & 63.6 & 13.7 & 13.5 \\
\hline & no & $35 / 68$ & 51.5 & 15.7 & 15.5 \\
\hline \multirow[t]{2}{*}{$\operatorname{CRP}(n=79)$} & $\leq 0.5 \mathrm{mg} / \mathrm{dL}$ & $33 / 63$ & 52.4 & 15.9 & 11.8 \\
\hline & $>0.5 \mathrm{mg} / \mathrm{dL}$ & $9 / 16$ & 56.3 & 13.6 & 12.0 \\
\hline Total & & $42 / 79$ & 53.2 & 16.65 & 15.4 \\
\hline
\end{tabular}

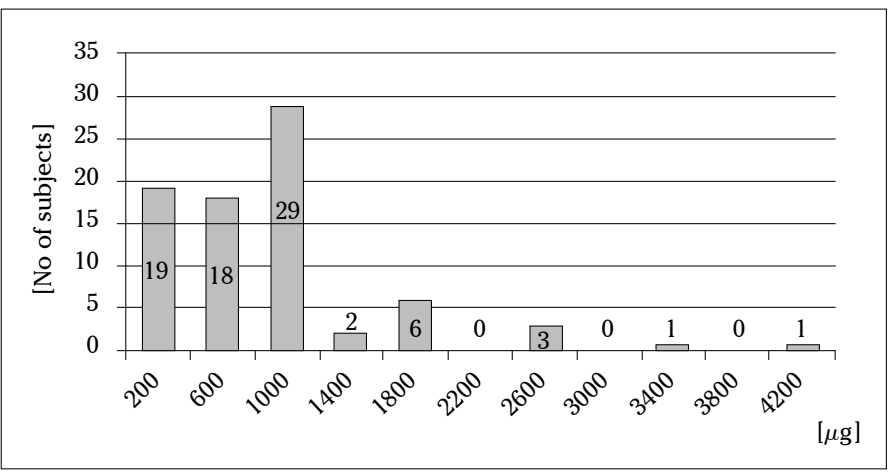

Figure 1. Number of women by total misoprostol dose

A total of $53.2 \%(42 / 79)$ of women delivered within 24 hours, and $83.6 \%$ (66/79) delivered within 48 hours. The most important factor impacting the induction-delivery time interval was history of late or early abortion: $83 \%$ of women with a history of late abortion delivered within 24 hours whereas $50.7 \%$ without this history did. Also, the mean induction-delivery time interval was 12.3 hours versus 35.5 hours $(p=0.09)$. A similar feature was seen in women with a history of early abortion; $65.2 \%$ vs. $48.2 \%$ delivered within 24 hours, and the mean induction- delivery time interval was approximately half as long for these women, i.e., 15.6 versus 32.5 hours $(p=0.075)$.

Fifty-five percent of women with current fetus weight $\leq 500 \mathrm{~g}$ delivered within 24 hours, whereas $33.3 \%$ did with a larger fetus. Time to delivery was also 2 hours less. Interestingly, a weight of last previous newborn of $\leq 3500 \mathrm{~g}$ facilitated timely delivery. A total of $61.5 \%$ of women delivered within 24 hours, approximately 6 hours faster than women with larger previous newborns (delivery within 12 hours vs. 18 hours). Slightly more women with previous pregnancies delivered within 24 hours ( 57.1 vs. $50.0 \%$ for nulligravidae); however, the mean inductiondelivery time interval was 4 hours shorter (13.5 vs. 17.1 hours). Premature rupture of membranes and an elevated CRP of $>0.5$ $\mathrm{mg} / \mathrm{dL}$ reduced the mean induction-delivery time interval by approximately 2 hours. Also, intrauterine fetal death slightly prolonged mean time to delivery ( $2 \mathrm{hrs}$ ). Surprisingly, the women's age and gestational age had no remarkable or consistent impact on the mean induction-delivery time interval (Table 3). None of the evaluations of the medical history and clinical variables reached statistical significance.

Figure 1 shows the number of women and their total misoprostol dose. The majority, $83.5 \%$ (66/79), needed $1000 \mu \mathrm{g}$ or less for 
Table 4. Total mean misoprostol dose by medical history

\begin{tabular}{|l|l|c|}
\hline \multicolumn{2}{|c|}{} & $\begin{array}{c}\text { Misoprostol } \\
\text { dose }(\boldsymbol{\mu g})\end{array}$ \\
\hline \multirow{2}{*}{ Age (years) (n=79) } & $\leq 30$ & 840 \\
\cline { 2 - 3 } & $>30$ & 965 \\
\hline \multirow{2}{*}{ Previous pregnancies $(\mathrm{n}=79)$} & 0 & 936 \\
\cline { 2 - 3 } & $>0$ & 886 \\
\hline Gestational age (weeks) $(\mathrm{n}=79)$ & $\leq 16$ & 1235 \\
\cline { 2 - 3 } & $>16$ & 819 \\
\hline \multirow{2}{*}{ Current weight of fetus $(\mathrm{n}=79)$} & $\leq 500 \mathrm{~g}$ & 912 \\
\cline { 2 - 3 } & $>500 \mathrm{~g}$ & 933 \\
\hline \multirow{2}{*}{$\begin{array}{l}\text { Premature rupture of membranes } \\
(n=79)\end{array}$} & yes & 818 \\
\cline { 2 - 3 } & no & 929 \\
\hline
\end{tabular}

successful delivery. That was one dose of $200 \mu \mathrm{g}$ on day 1 and $2 \times 200 \mu \mathrm{g}$ on days 2 and 3 .

Table 4 shows the total mean misoprostol dose by medical history. Only for women with a gestational age of $\leq 16$ weeks did the mean misoprostol dose exceed $1000 \mu$ g (i.e., $1235 \mu$ g).

Six women $(7.6 \%)$ suffered prolonged bleeding post-surgery, reaching anemia of $<9.5 \mathrm{~g} / \mathrm{dL}$ hemoglobin, but no blood transfusions were necessary. Two women experienced fever (data not shown).

\section{Discussion}

In an attempt to define the role of medical history and/or clinical variables for the prediction of time to delivery in the second trimester, we performed a retrospective chart analysis on 79 women. All were submitted for pre-term labor induction due to fetal and amniotic fluid anomalies, i.e, chromosome aberrations, PROM, or a wide spectrum of malformations.

We defined the percentage of women delivering within 24 hours as the primary endpoint, a well-established measure for successful abortion induction $(2,3)$. After repeated vaginal application of misoprostol, overall, $53 \%$ of women delivered within 24 hours. This result is well in line with other studies, irrespective of the misoprostol dose: Kolderup reported a success rate of $77 \%$ (4), whereas Manjunath (5) even reached $82.4 \%$. However, all of these studies were relatively small, and the group of women might not be directly comparable with respect to all of the relevant medical history and/or clinical baseline characteristics. Our secondary endpoint, the mean time to delivery, is of more practical use for patient counseling, as it provides the treating physician a rough estimate of the induction-delivery time interval for a specific subject with a unique medical history and clinical profile. Here, we feel our data are unique.

Our analysis of the impact of previous late or early abortions on successful delivery within 24 hours is somewhat innovative, as we were not able to find comparable studies in the current literature. Our data show that a total of $83.3 \%$ (5/6) of women with a history of late abortion delivered within 24 hours, whereas $50.7 \%(37 / 73)$ without this history did. This finding is supported by the mean induction-delivery time interval, which was 12.3 hours and 35.5 hours, respectively $(\mathrm{p}=0.09)$. Although this result does not reach statistical significance - most probably due to the small sample size - we tend to suggest at least a positive trend for late abortions in the medical history to abbreviate the induction-delivery time interval for later abortions. We would propose further research to investigate whether or not persistent cervical infections, which frequently cause late abortions, might impact cervical ripening during induction of abortion.

We found a similar effect for history of early abortion: $65.2 \%$ (15/23) delivered within 24 hours compared to $48.2 \%$ (27/56) without this history. The mean induction-delivery time interval confirmed this trend, with results of 15.6 hours versus 32.5 hours $(p=0.075)$. Here, the sample sizes were more balanced but still not sufficient to confirm statistical significance.

Weight of fetus $\leq 500 \mathrm{~g}$ increased the likelihood of successful delivery within 24 hours. As the vast majority of our cohort consisted of women seeking pre-term abortion in the second trimester, $92.4 \%(73 / 79)$ of women bore a fetus of $\leq 500 \mathrm{~g}$. The median fetus weight was $240 \mathrm{~g}$. Interestingly, we did not find any similar reports on pre-term labor induction in the recent literature just for labor induction in the third trimester. Crane et al. (3) reported a direct correlation between lower birth weight and delivery within 24 hours and also a lower rate of cesarean sections, quite obvious findings. However, these results are barely comparable with ours.

A limitation of our findings is the somewhat poor accuracy of the pre-natal weight assessment. In our study, we used the precise results of postpartum weights, but for patient counseling, one must rely on pre-natal assessments by ultrasound, which feature a variation of about $15 \%$ on average, depending on the quality of the method of measurement, the ultrasound technique, and the experience of the operator (5).

Premature rupture of membranes and an elevated CRP of $>0.5$ $\mathrm{mg} / \mathrm{dL}$ also shorten time to delivery by approximately 2 hours. Again, we were unable to find a comparable trial in the recent literature. Only Mbele et al. (6) showed a significantly reduced time to delivery after premature rupture of membranes but in a cohort of women with full-term pregnancies.

Surprisingly, the women's age and gestational age had no remarkable or consistent impact on the mean induction-delivery time interval. Although slightly more women with gestational age $\leq 16$ weeks delivered within 24 hours $(53.2 \%$ vs. $47.1 \%$ for women $\leq 16$ weeks), the mean time to delivery was almost 15 hours for both groups. Edwards et al. (7), Murchison et al. (8), and Lister et al. (9) investigated different regimens of misoprostol for first-trimester abortions in similar cohorts as ours. The success rates varied from $54 \%$ and $81 \%$ (8) to $78 \%$ (9) and $83 \%$ (10). Unfortunately, no separate evaluations by gestational age were reported. Only data on misoprostol and gestational age are available for the third trimester. Wing et al. (2) studied a cohort of 1373 women and found a significant positive correlation between gestational age and successful delivery within 24 hours-i.e., the higher the gestational age, the shorter the delivery time. In addition, the more advanced the pregnancy, the smaller the misoprostol dose that was needed.

The major limitations of our study are not only the small sample size and the multitude of anamnestic and clinical variables but 
also the wide range of gestational ages (including the different density of myometrial receptors for contractile agents) and the diversity of indications leading to the induced abortion. In order to get scientifically robust and statistically convincing results, a cohort is needed that allows for clustering of variables, i.e, looking at women that differ just for one variable. Such a study design, however, is only possible in a large multicenter approach.

In this study, we tried to define the role of medical history and/ or clinical variables for prediction of time to delivery for a cohort of women in the second trimester. Although our results did not reach statistical significance, most reasonably due to the small sample size, we saw at least trends for certain variables. We provide approximations for the mean induction-delivery time interval, which might serve as some preliminary guidance for the physician. Only few studies in a similar cohort have been reported so far. More knowledge is available for the third trimester, which is, however, not really comparable. In addition, the few studies with a similar study design did not analyze the findings in such a detailed manner as we did. Eventually, due to the paucity of findings on the subject reported here, even our non-significant results could be considered a valuable contribution to broaden our understanding of the duration of pre-term abortion induction.

In conclusion, neither variables of medical history nor specific clinical variables allow for precise prediction of time to delivery in the second trimester. Certain parameters, such as history of late/early abortions, current weight of fetus $>500 \mathrm{~g}$, weight of last previous newborn $\leq 3500 \mathrm{~g}$, previous pregnancies, premature rupture of membranes, and elevated CRP of $>0.5 \mathrm{mg} / \mathrm{dL}$, however, show a trend to reduce the induction-delivery time interval. Our results might serve as initial guidance for patient counseling, which is crucial for compliance. Eventually, wellfounded information about the abortion course could improve the psychological situation.

Ethics Committee Approval: N/A.

Informed Consent: $N / A$

Peer-review: Externally peer-reviewed.
Author contributions: Concept - A.dL., K.E., S.F.; Design - A.dL., K.E., S.F.; Supervision - A.dL., K.E., S.F., E.S.; Resource - A.dL., S.F.; Materials - A.dL., S.F.; Data Collection\&/or Processing A.dL., J.E., S.F.; Analysis\&/or Interpretation - A.dL., K.E., S.F., J.E., E.S.; Literature Search - S.F., J.E.; Writing - J.E., S.F.; Critical Reviews - A.dL., K.E., S.F., J.E.,E.S.

Conflict of Interest: No conflict of interest was declared by the authors.

Financial Disclosure: The authors declared that this study has received no financial support.

\section{References}

1. Weeks AD, Fiala C, Safar P. Misoprostol and the debate over offlabel drug use. BJOG 2005; 112: 269-72. [CrossRef]

2. Wing DA, Tran S, MD, Paul RH. Factors affecting the likelihood of successful induction after intravaginal misoprostol application for cervical ripening and labor induction. Am J Obstet Gynecol 186; 2002: 1237-43. [CrossRef]

3. Crane JM, Delaney T, Butt KD, Bennett KA, Hutchens D, Young DC. Predictors of successful labor induction with oral or vaginal misoprostol. J Matern Fetal Neonatal Med 2004; 15: 319-23. [CrossRef]

4. Kolderup L, McLean L, Grullon K, Safford K, Kilpatrick SJ. Misoprostol is more efficacious for labor induction than prostaglandine E2, but is it associated with more risk? Am J Obstet Gynecol 1999; 180: 1543-50. [CrossRef]

5. Dudley NJ. A systematic review of ultrasound estimation of fetal weight. Ultrasound Obstet Gynecol 2005; 25: 80-9. [CrossRef]

6. Mbele AM, Makin JD, Pattison. Can the outcome of induction of labour with oral misoprostol be predicted? S Afr Med J 2007; 97: 289-92.

7. Edwards RK, Sims SM. Outcomes of second-trimester pregnancy terminations with misoprostol: Comparing two regimens. Am J Obstet Gynecol 2005; 193: 544-50. [CrossRef]

8. Murchison A, Duff P. Misoprostol for uterine evacuation in patients with early pregnancy failures. Am J Obstet Gynecol 2004; 190: 1445-6. [CrossRef]

9. Lister MS, Shaffer LE, Bell JG, Lutter KQ, Moorma KH. Randomized, double-blind, placebo-controlled trial of vaginal misoprostol for management of early pregnancy failures. Am J Obstet Gynecol 2005; 193: 1338-43. [CrossRef] 